Title:

Authors:

Source:

Document Type:

Subject Terms:
Fitness: a viable adjunct to treatment for young adults with psychiatric disabilities

Karen V. Unger, Gary S. Skrinar, Dori S. Hutchinson and Ann M. Yelmokas

Psychosocial Rehabilitation Journal; Jan92, Vol. 15 Issue 3, p20, 8p, 1 Chart

Article

*MENTALLY ill

*EXERCISE

*HEALTH

PSYCHOLOGICAL aspects

Examines the role of physical illness as a factor of mental illness and the positive effects of exercise on psychological functioning. Study of six persons participating in a fitness program as an adjunct to an existing psychoeducational program.

\title{
FITNESS: A VIABLE ADJUNCT TO TREATMENT FOR YOUNG ADULTS WITH PSYCHIATRIC DISABILITIES
}

Abstract: The role of physical illness as a factor of mental illness and the positive effects of exercise on psychological functioning are examined A study of six persons who participated in a fitness program as an adjunct to an existing psychoeducational program is discussed. Methodology, description of the students, results, and personal responses to the fitness program are described. outcomes include a slight decrease in body fat and an increase in cardiovascular fitness as measured by oxygen intake. Although a formal measure of self esteem did not show changes over the course of the study, students report positive attitude changes. An exercise compliance rate of $81 \%$ and improved fitness indicate that persons with severe psychiatric disabilities will participate in and can benefit from an exercise program.

\section{Introduction}

There are approximately 1.7 to 2.4 million people in the United States who are severely psychiatrically disabled (Goldman, Gattozzi, \& Yawke, 1981). Persons with severe psychiatric disabilities, in addition to their mental illness, also frequently suffer the adverse effects of poor physical fitness, including weight problems, poor sleep habits, poor cardiovascular fitness, sluggishness, low energy, poor body image, and low self-concept. These conditions represent serious barriers to the rehabilitation of those persons who have psychiatric disabilities.

People with psychiatric disabilities have a need for basic health services that is often neglected. A decade of research shows consistently high rates of physical illness in all groups of psychiatric patients. In a review of 12 studies, Koranyi (1980) found major medical illness in up to 50\% of all psychiatric patients. The same rate was found in a meta-analysis of four studies of psychiatric inpatients (Hoffman \& Koran, 1984). In a more recent review of this research, weighted prevalence rates of physical illness were found to be $37 \%$ for psychiatric inpatients and 38\% for psychiatric outpatients (Maricle, Hoffman, Bloom, Faulkner, \& Keepers, 1987). Using aggregate data, Taube and associates found that one third of all heavy users of mental health outpatient services had multiple medical problems (Taube, Goldman, Burns, 
\& Kessler, 1988).

Several studies have found that in $5 \%$ to $28 \%$ of the cases (Hall, Gardner, Popkin, Lecann, \& Stickney, 1981; Koranyi, 1982; Hoffman \& Koran, 1984) unrecognized physical illness can actually be the primary cause of the psychiatric symptoms. This leads to the conclusion that appropriate health care intervention could reduce the need for mental health services. As one component of health care intervention, awareness of the need for a physical fitness program can enhance basic health care. By increasing the attention of the role of fitness in overall ability to function productively, health consciousness, health maintenance, and disease prevention can become secondary outcomes of a physical fitness program.

Research studies examining the effects of physical exercise on fitness and self-concept are still relatively sparse, particularly with subjects exhibiting severe psychiatric disability. The available findings do seem to support the hypothesis that physical exercise enhances physical and mental health in this population (Collingwood \& Willet, 1971; Conroy, Smith, \& Felthous, 1982; Gary \& Guthrie, 1972; Heaps, 1978; Ishmail \& Young, 1977; Quinn, 1982; Rosenthal \& Beutell, 1981). The physical and psychological benefits of an individualized exercise program for "normal" adults were evaluated by Wilfley and Kunce (1986). Statistically significant improvements were shown in terms of physical self-concept and reduced psychological tension.

Inactivity and isolation are often associated with mental illness. This may be a consequence of specific pathology such as depression or it may be due to circumstances such as institutionalization, poor cardiovascular fitness, deficient diet and nutrition, or the effects of medication. A number of investigations have suggested that such individuals who are physically and psychologically in poor condition will demonstrate physical and psychological progress in these areas following involvement in physical activity (Folkins, Lynch \& Gardner, 1972; Gutin, 1966; Hellison, 1970; Layman, 1974).

In relation to overall rehabilitation outcomes, Egri and Canton (1982) state that the factors that most seem to influence rehabilitation are frustration tolerance, quality of judgment, ability to plan towards a goal, ability to delay gratification, and toleration of stress without resorting to substance abuse or acting out. For persons with psychiatric disabilities who possess these attributes, there is the potential to grow, to change their behavior, and to develop a healthier self-concept. Improved physical fitness may lead to improved selfesteem, improved physical appearance, increased ability to handle stress, increased energy, and more positive affect. These factors may all effect rehabilitation outcome and contribute to the development of the factors listed by Egri and Canton (1982).

\section{Methodology}

A study was conducted to measure the impact of fitness training on cardiovascular fitness, body composition (percentage of fat) and self-esteem of young adults with psychiatric disabilities. The purpose of the study was 1) to demonstrate the ability of young adults with severe psychiatric disabilities to participate in a fitness training program, and 2) to determine if persons with psychiatric disabilities would benefit from a fitness program in relation to key cardiovascular and psychological variables.

\section{Method}

Participants, who volunteered for the study, were students with psychiatric disabilities enrolled in a psychoeducation program at a university. Training took place at a gymnasium on campus. The program primarily utilized cardiovascular fitness equipment (stationary cycles, rowing machines, stair climbing), and some flexibility and muscle strengthening exercises, as the training regimen. As the participants became comfortable with the equipment and the routine, activities such as a run-walk program and low impact aerobics were included. Two exercise leaders and a psychiatric rehabilitation counselor from the psychoeducation program provided instruction, support, and ongoing supervision.

Baseline data were collected before the physical fitness training began and consisted of a comprehensive fitness assessment conducted by a cardiologist and an exercise physiologist. Cardiovascular fitness was measured by a standard exercise test administered at the fitness center. This evaluation provided the necessary information needed to determine an exercise training heart rate for each individual in the program. Fingertip blood samples were taken to assess total cholesterol levels. Skinfold calipers were used to assess body fat composition. All measures were taken 1 week prior to participation and again at the completion of the program. The instrument used to measure psychological variables was the Rosenberg Self-Esteem Inventory (Rosenberg, 1965).

Program participants were required to obtain permission from their personal physician and psychiatrist in order to engage in the fitness program. Participants found to have hypertension and/or high cholesterol during the initial assessment were to be excluded from participation in the program. None were excluded because of these conditions. 
Each fitness class was divided into 30 minutes of aerobic activity and 30 minutes of flexibility and strengthening exercises. A progressive approach was used, with initial classes starting with only 10 to 15 minutes of aerobic exercise. This increased to 30 minutes after the fifth week. Students self-selected the type of aerobic exercise they would do, with combinations of rowing, stationary cycling, stair climbing, or race-walking. Fitness instructors monitored pulse rates to ensure they were reaching their previously determined target heart rate. Students were taught to cool down properly after exercising. Personal goals were written at the beginning of the program. Exercise goals were set regarding intensity of aerobic exercise, number of push-ups and abdominal exercises, flexibility, smoking, weight loss, body fat composition, and nutritional habits. Educational topics concerning nutrition, smoking, muscle soreness, benefits of exercise, and cholesterol were regularly discussed at the end of class. Literature on many of these topics was provided to the participants. Although compliance to the program was exemplary, students who missed classes were encouraged to schedule a make-up session.

At the end of the 10 weeks, students met individually with the fitness instructors to review their progress and goals and discuss the results of their post-fitness test. The instructors helped them plan an individualized fitness program that they could implement on their own after the completion of the course. They also encouraged students to take advantage of the fitness courses offered at the university as a way to maintain their achieved fitness levels.

\section{Description of the Students}

Students who participated in the fitness program had been enrolled in the psychoeducational program and were receiving some form of follow-up services from program staff members. of the 40 potential participants offered the program, nine volunteered for the initial screening. Six completed the program.

Table 1 presents a profile of the participating students and their psychiatric history.

\section{Outcomes}

The tentative findings of the project suggest:

This population can safely participate and comply (81\%) in an exercise program if it starts gradually and is monitored to maintain appropriate intensity.

Participants' body composition (percentage of fat) was modestly lowered in half of the subjects by approximately $2 \%$. However, at a frequency of two supervised sessions per week and the limited duration of aerobic activity, only minimum change could be expected.

Participants' cardiovascular fitness level as measured by oxygen intake significantly improved over the course of the training.

Cholesterol levels averaged 189 on the pre-test and were considered in the low risk category. The levels may also reflect the influence of various psychotropic medications. Levels did not change significantly on the post test.

Students were able to increase the number of abdominal curls from one set of 20 to 5 sets of 25 , and push-ups from one set of 10 to 4 sets of 15 .

The self-report questionnaire on self-esteem did not show changes. over the course of the study. However, participants described positive attitudinal and behavior changes not reported by the assessment tool. 7. Participants tolerated the cardiovascular testing procedures very well. In addition to the outcomes cited above, each student achieved several of his or her personal goals. one person quit smoking and another cut his consumption of cigarettes in half. All implemented nutritional changes such as switching from caffeinated to decaffeinated coffee, eating breakfast, and cutting down on the amount of sugar in their diets. Most reported more walking during the day.

In an exit interview conducted at the completion of the fitness program, all students reported feeling much better. More specifically, statements were made about improved mental status, decreased anxiety, improved coping, increased self-esteem, and increased energy level. It was apparent that sociatization was a major factor in the enjoyment of and participation in the class.

\section{Follow-up}

During a follow-up interview 16 weeks after the program ended, most of the students reported exercising for the 2 months following the program. After the end of the second month the exercise frequency decreased, but all of the students reported wanting to resume regular exercise and were making an effort to do so. The majority of students reported continued improvement in both regularity of eating and kinds of food eaten. Also reported was the maintenance of the ability to better handle stress. However, the five students who smoked at the beginning of the fitness program and reduced smoking during the exercise regime did not maintain the reduced level of smoking. 
In summary, the fitness program appeared to be a very positive experience for all participants. Conversations with students a year later indicated that two of them had enrolled in a formal fitness program and others were maintaining physical activity on their own.

\section{Discussion}

Young adults with psychiatric disabilities are described in the literature as unable to work towards realistic goals, unable to relate to others, possessing a limited capacity to endure stress, and possessing extreme dependency (Stein \& Test, 1982). Although it is not appropriate to generalize about the population of persons with psychiatric disabilities from a population sample of 6 , participants in this study have moved beyond the above description. The participation in the program and the additional work in the fitness program helped participants to set and work toward achieving realistic goals, to relate well to others, to tolerate the stress of new environments and new experiences that were physically challenging, and to maintain a degree of independence as exercise programs were continued independently.

In examining the results of this study, it is also important to comment on the effects of the medications students were taking. All students were taking one or more medications during the fitness program. The medications included Artane, Ativan, Elavil, Haldol, Lithium, Lithium Carbonate, Loxitane, Prolixin, and Xanax. The side effects of those psychotropic medications may include the following: muscular rigidity, dehydration, muscle weakness, fatigue, impaired coordination, and many others. Motivation is often the primary factor in completing a successful exercise program. In addition to the problems experienced by most people, the compounding problems posed by the side effects of the medication for the participants were staggering. However, the attendance rate of 810/o speaks to the desire to participate and complete the program. The structure of the program, the supportive staff and the perceived physical and emotional benefits all seem to be factors contributing to program success.

\section{Summary}

It is clear from the review of the literature that there is a critical need for research to identify the knowledge and skills for providing physical fitness training to persons with severe psychiatric disabilities. If exercise training can improve physical fitness, increase the awareness of the importance of health care, increase the ability to handle stress, enhance self-esteem, and decrease dysphoric affect among individuals with severe psychiatric disability, their overall rehabilitation potential could be greatly increased.

Table 1

Students Profiles

$\begin{array}{lccccc}\text { Student } & \text { Sex } & \text { Age } & \text { Dignosis } & \begin{array}{c}\text { Age of } \\ \text { Onset }\end{array} & \begin{array}{c}\text { Lenght of } \\ \text { Hospitalization }\end{array} \\ 2 & \text { M } & 33 & \text { affective disorder } & 19 & 3 \text { months } \\ 3 & \text { F } & 40 & \text { severe borderline } & 21 & 20 \text { months } \\ 4 & \text { M } & 34 & \text { affective disorder } & 9 & 0 \\ 5 & \text { M } & 38 & \text { affective disorder } & 20 & 45 \text { months } \\ 6 & \text { F } & 28 & \text { schizophrenia } & 18 & 16 \text { months } \\ & \text { M } & 27 & \text { other psychosis } & 21 & 16 \text { months }\end{array}$

\section{REFERENCES}

Collingwood, T., \& Willet, L. (1971). The effects of physical training upon self-concept and body attitudes. Journal of Clinical Psychology, 27, 441-412.

Conroy, R., Smith, K., \& Felthous, A. (1982). The value of exercise on a psychiatric hospital unit. Hospital and Community Psychiatry, 33, 641-645.

Egri, G., \& Canton, C. L. (1982). Serving the young adult chronic patient in the 1980's: Challenge to the general hospital. In B. Pepper \& H. Ryglewicz (Eds.), The young adult chronic patient (pp. 25-31). San 
Francisco: Jossey-Bass, Inc.

Folkins, C. H., \& Sime, W. E. (1981). Physical fitness training and mental health. American Psychologist, 36(4), 373-389.

Gary, V., \& Guthrie, D. (1972). The effect of jogging on physical fitness and self-concept in hospitalized alcoholics. Quarterly Journal of Studies on Alcoholism, 33, 1079-1083.

Goldman, A., Gattozzi, C., \& Yawke, D. (1981). Defining and counting the chronically mentally ill. Hospital and Community Psychiatry, 32(1), 259.

Gutin, B. (1966). Effect of increase in physical fitness in mental ability following physical and mental stress. Research Quarterly, 37, 211-220.

Hall, R. C., Gardner, E. R., Popkin, M. K., Lecann, A. E, \& Stickney, S. K. (1981). Unrecognized physical illness prompting psychiatric admission: A prospective study. American Journal of Psychiatry, 138, 629635.

Heaps, R. A. (1978). Relating physical and psychological fitness: A psychological point of view. Journal of Sports Medicine and Physical Fitness, 18, 399-408.

Hellison, D. R. (1970). The effect of physical conditioning on affective attitudes toward the self, the body and physical fitness. Dissertation Abstracts International, 30-A, 2831. (University Microfilms, No. 69-22, 142, b.)

Hoffman, R. S., \& Koran, L. M. (1984). Detecting physical illness in patients with mental illness. Psychosomatics, 25(9), 654-659.

Ishmail, A. H., \& Young, R. J. (1977). Effects of exercise on the personality of adults. Annals of the New York. Academy of Science, 301, 958-969.

Koranyi, E. K. (1980). Somatic illness in psychiatric patients. Psychosomatics, 21, 887-891.

Koranyi, E. K. (1982). Undiagnosed physical illness in psychiatric patients.AnnualReviewof Medicine, 33, 309-316.

Layman, E. (1974). Psychological effects of physical activity. Exercise and Sports Sciences Review, 3370.

Maricle, R. A., Hoffman, W. E, Bloom, J. D., Faulkner, L. R., \& Keepers, G. A. (1987). The prevalence and significance of medical illness among chronically mentally ill outpatients. Community Mental Health Journal, 23, 8 1-90.

Quinn, P. (1982). The effects of a graded exercise program on the physical fitness functioning level, selfconcept, body image, and behavior of the chronic psychiatrically disabled. Unpublished doctoral dissertation, Boston University, Sargent College of Allied Health Professions Department of Rehabilitation Counseling.

Rosenberg, M. (1965). Society and the Adolescent Self-Image. Princeton, NJ: Princeton University Press.

Rosenthal, M., \& Beutell, N. (1981). Movement and body-image: A preliminary study. Perceptual and Motor Skills, 53, 758.

Stein, L., \& Test, M. (1982). Community treatment of the young adult patient. In B. Pepper and H. Ryglewicz (Eds.), The young adult chronic patient (pp. 57-67). San Francisco: Jossey-Bass, Inc.

Taube, C. A., Goldman, H. H., Burns, B. J., \& Kessler, L. G. (1988). High users of outpatient mental health services: Vol. 1. Definition and characteristics. American Journal of Psychiatry, 145(1), 19-24.

Wilfley, D., \& Kunce, J. (1986). Differential physical and psychological effects of exercise.Journal of Counseling Psychology, 33(3), 337-342. 
By Karen V. Unger, Gary S. Skrinar, Dori S. Hutchinson and Ann M. Yelmokas

Karen V. Unger, M.S.W., Ed.D., is Director of Supported Education Dissemination at the Center for Psychiatric Rehabilitation at Boston University. She has published and lectured nationwide on the topic of young adults with psychiatric disabilities. Gary S. Skrinar, Ph.D., is an associate professor in the Department of Health Sciences at Sargent College of Allied Health Professions at Boston University. As an exercise physiologist and Director of the Health Sciences Fitness Center, he has conducted research on exercise training and its benefits for women, people with physical disabilities, and people with psychiatric disahilities. Dori S. Hutchinson, M.S., is Coordinator of Instructional Services for the Career Education Program at the Center for Psychiatric Rehabilitation and an instructor in the Rehabilitation Counseling Department at Sargent College of Allied Health Professions at Boston University. Ann M. Yelmokas, M.S., is Aquatic Director at Simmons College in Boston, Massachusetts, and has worked extensively in the field of adult fitness for the past 12 years.

Copyright of Psychosocial Rehabilitation Journal is the property of Trustees of Boston University IAPSRS and its content may not be copied or emailed to multiple sites or posted to a listserv without the copyright holder's express written permission. However, users may print, download, or email articles for individual use. 